http://ejournal.upi.edu/index.php/jaz - e-mail: jurnal_zonasi@upi.edu doi.org/10.17509/jaz.v4i2.31295

\title{
KAJIAN KONSEP FEMINISME PADA BANGUNAN PUSAT KECANTIKAN (Erha Derma Center, Tangerang)
}

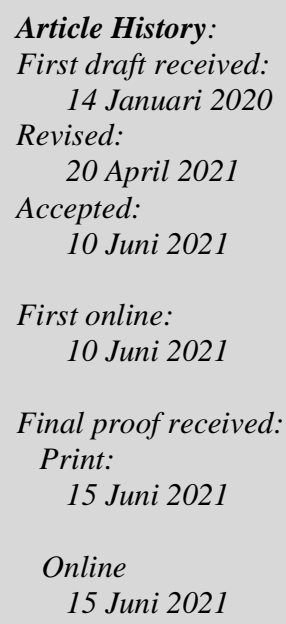

Jurnal Arsitektur ZONASI is indexed and listed in several databases:

SINTA 4 (Arjuna)

GARUDA (Garda Rujukan Digital)

Google Scholar

Dimensions

oneSearch

BASE

Member:

Crossref

RJI

APTARI

FJA (Forum Jurna Arsitektur)

IAI

AJPKM

\author{
Almira Muthi Faliha \\ Yeptadian Sari \\ 1,2,3 Universitas Muhammadiyah Jakarta,Jakarta,Indonesia \\ Jl. Cempaka Putih Tengah 27, RT.11/RW.5, Cemp. Putih Tim., Kec. Cemp. Putih, Kota \\ Jakarta Pusat, Daerah Khusus Ibukota Jakarta 10510 \\ Email: almiramuthi@gmail.com \\ Yeptadian.sari@ftumj.ac.id
}

\begin{abstract}
The times have made the technology era more sophisticated, this can affect the lifestyle of people in social interaction, especially women. Women often feel insecure in social interactions. It makes women beautify by taking care of themselves at the beauty center. In order to create a beauty center in accordance with its function, which supports women in expressing themselves, the authors apply the concept of feminism to the building of the beauty center. The case study that will be discussed in this study is the Erha Derma Center which is located in BSD Serpong, while the method used is a qualitative description and the results of research that have been reviewed from the Erha Derma Center building can be said that the building has implemented the concept of feminist architecture. This is because the shape of the building has a curved shape and has a unique character, then the facade uses glass as the main material, and uses soft colors both on the interior and exterior of the building, and has a clear space with a wall divider in each space.
\end{abstract}

Keywords: Women, Feminist Architecture, Beauty Center

Abstrak: Perkembangan zaman membuat era teknologi semakin canggih, hal tersebut dapat mempengaruhi gaya hidup masyarakat dalam berinteraksi sosial, khususnya bagi perempuan. Perempuan sering kali merasa tidak percaya diri dalam berinteraksi sosial. Hal itu membuat perempuan mempercantik dengan merawat dirinya ke pusat kecantikan. Agar terciptanya pusat kecantikan sesuai dengan fungsinya, yang mendukung perempuan dalam mengekspresikan dirinya maka penulis menerapkan konsep feminisme pada bangunan pusat kecantikan. Adapun studi kasus yang akan dibahas dalam kajian ini yaitu erha derma center yang lokasinya berada di BSD Serpong, sedangkan metode yang akan digunakan adalah deskripsi kualitatif dan hasil dari penelitian yang telah dikaji dari bangunan erha derma center dapat dikatakan bahwa bangunan tersebut sudah menerapkan konsep arsitektur feminisme. Hal tersebut karena bentuk bangunan memiliki bentuk yang melengkung serta memiliki karakter yang unik, kemudian fasad menggunakan kaca sebagai bahan utama, dan menggunakan warna-warna yang lembut baik pada interior maupun eksterior bangunan, serta memiliki ruang yang jelas dengan diberi pembatas dinding pada setiap ruangnya.

Kata Kunci: Perempuan, Arsitektur Feminisme, Pusat Kecantikan

\section{Pendahuluan}

Pada era globalisasi teknologi semakin berkembang dengan pesat baik teknologi informasi maupun komunikasi. Berbagai informasi dari penjuru dunia dapat langsung diketahui melalui adanya teknologi. Teknologi yang semakin canggih sangat memudahkan manusia dalam berinteraksi, hal itu dapat mempengaruhi pola hidup masyarakat dalam berinteraksi sosial, khususnya bagi perempuan. Perempuan sering kali kehilangan kepercayaan diri untuk berperan aktif di depan banyak orang atau saat berinteraksi sosial (Sya'bania et al., 2019). Pada dasarnya setiap manusia memiliki keinginan untuk berpenampilan sempurna 
saat berinteraksi sosial terutama bagi perempuan, keinginan inilah yang membuat kekhawatiran seseorang timbul dan kekhawatiran ini akan menjadikan seorang manusia melakukan hal-hal agar penampilannya terlihat menarik seperti apa yang diinginkan (Thompson, 2007). Untuk memenuhi hal tersebut kaum perempuan harus lebih ekstra membuka pemikiran bagaimana cara mereka mengekspresikan dirinya agar merasa tidak takut dalam berinteraksi sosial secara normal pada umumnya. Karena pada dasarnya kecantikan merupakan sesuatu hal yang sangat melekat bagi kaum perempuan (Badu et al., 2019). Salah satu solusi yang dapat diwujudkan untuk mengatasi permasalahan tersebut adalah menghadirkan sebuah pusat kecantikan yang mampu mewujudkan kebutuhan kaum perempuan untuk memperbaiki penampilan sekaligus menjaga keseimbangan tubuh, pikiran dan jiwa. Agar terciptanya pusat kecantikan sesuai dengan fungsinya yang mendukung perempuan dalam mengekspresikan dirinya maka dibutuhkan konsep feminisme pada arsitekturnya.

Feminisme dapat diartikan, bahwa seseorang menunjukan sikap yang lembut. Akan tetapi feminisme adalah salah satu sifat yang lebih cenderung dimiliki kaum perempuan. Selain itu feminisme berawal dari sebuah gerakan perempuan yang menuntut kesetaraan terhadap laki-laki. Hal ini merupakan bentuk sikap perempuan untuk memperjuangkan keadilannya, salah satunya dalam bidang arsitektur. Dapat kita temui bahwa feminisme muncul sebagai penolakan dominasi pria pada era post-modern. Arsitektur Post-Modern kebanyakan laki-laki lebih memegang peranan penting dalam perubahan dunia arsitektur, melihat hal ini para arsitek perempuan menuntut persamaan kedudukannya (Silaban \& Punuh, 2011)

Berdasarkan uraian diatas maka perlu maka dapat ditarik suatu rumusan masalah yang akan dibahas yaitu bagaimana penerapan prinsip arsitektur feminisme pada bangunan pusat kecantikan Erha Derma Center Tangerang, agar dapat memahami langkah-langkah yang perlu dipertimbangkan untuk membuat pusat kecantikan sesuai dengan fungsinya dan membuat kaum perempuan merasasakan kenyamanan dan keamanan saat berada didalam bangunan tersebut. Oleh karena itu, penulis mengangkat penelitian yang berjudul "Kajian konsep feminisme pada bangunan pusat kecantikan" guna mendapatkan gambaran lebih dalam penerapan konsep feminisme pada bangunan pusat kecantikan.

\section{Sejarah Feminisme}

Menurut (Retnani, 2017) feminisme atau tokohnya yang disebut feminis adalah gerakan bagi perempuan untuk memperjuangkan kesetaraan dan keadilan dengan laki-laki. Sampai saat ini pada zaman dahulu wanita pernah mengalami kenyataan pahit, mereka dianggap tidak berdaya, lemah dan selalu menjadi nomor dua. Berbagai bentuk diskriminasi dan perlakuan tidak adil terhadap perempuan telah menyebabkan perempuan memberontak dengan melakukan gerakan kecil-kecilan untuk memperjuangkan hak-haknya sebagai manusia. Pertemuan tersebut dipandu oleh Elizabeth Candi dan rekannya Susan Anthony di New York. Pada dasarnya, feminisme memiliki klaim tak terbantahkan bahwa perempuan ditindas dan bertindak sesuai dengan itu. Kemudian pada tahun 1848, sejumlah wanita berkumpul di New York dan menuntut larangan berbicara di depan umum bagi wanita untuk memperjuangkan hak-hak mereka. Kemudian, pada tahun 1850, parlemen negara bagian Amerika Serikat mulai menunjukkan rasa simpati terhadap gerakan konferensi.

Pada abad yang sama, Feminis Indonesia RA Kartini mendirikan kemerdekaan Indonesia melalui korespondensi dengan feminis Belanda Stella Zeehandelaar. Surat-surat tersebut digabungkan menjadi sebuah buku Habis Gelap Terbitlah Terang, yang mengatakan bahwa setiap manusia akan mengalami masa-masa sulit, tetapi juga akan merasakan masa-masa membahagiakan.Dimana seorang feminis asal Indonesia RA.Kartini telah mengalami perlakuan tidak adil, kala itu kartini tidak diperkenankan untuk mengikuti pendidikan tinggi seperti saudara laki-lakinya yang dapat melanjutkan sekolah hingga masuk ke perguruan tinggi di Belanda. Hal itu membuat kartini keluar dari sekolah dan berdiam diri dirumah selama 4 tahun dalam masa pingitan. Pada akhirnya, Kartini memantapkan keinginan untuk merasa dirugikan melalui pendidikan dengan membangun sekolah untuk anak perempuan di wilayahnya (Melati, 2020).

\section{Tujuan Feminisme}

Berikut tujuan terbentuknya gerakan feminisme antara lain (Amin, 2013):

- Membuka kesetaraan perlakuan terhadap perbedaan gender sebagai pengontrol sosial.

- Feminisme hadir untuk mendobrak sistem sosial yang dimana laki-laki lebih berkuasa atau mendominai dari pada perempuan.

- Terbentuknya feminisme yaitu untuk membela hak dan partisipasi perempuan dalam masyarakat seiring berkembangnya budaya dan struktur masyarakat yang semakin membedakan laki-laki dan perempuan di lingkup politik, ekonomi, pribadi, dan sosial.

- Keseimbangan gender dan hubungan timbal balik.

\section{Aliran-Aliran Feminisme}


Menurut (Silaban \& Punuh, 2011) walaupun sama-sama mendukung feminisme mengenai pentingnya kesetaraan antara laki-laki dan perempuan, tetapi para feminis memiliki pandangan mengenai kesetaraan tersebut. Aliran-aliran dalam arsitektur feminisme sebagai berikut:

a. Feminisme Liberal

Aliran ini muncul pada abad ke-19, dimana aliran ini menyatakan bahwa kebebasan berakar pada rasionalitas dan pemisahan antara ruang privat dan publik. Karena pada dasar nya perempuan adalah makhluk sosial yang mempunyai kemampuan sama dengan laki-laki, sehingga harus diberikan hak yang sama dengan laki-laki.

b. Feminisme Radikal

Feminisme radikal muncul pada abad ke-19 yang mengangkat isu mengenai perlawanan terhadap gerakan partiarki atau menempatkan laki-laki sebagai pemegang kekuasaan utama. Tubuh perempuan merupakan objek utama penindasan oleh kekuasaan laki-laki.

c. Feminisme Multikultural

Aliran ini muncul pada tahun 1960-an, Bagi feminis multikultural, setiap perempuan memiliki pengalaman yang berbeda-beda pada setiap individunya. Aliran ini percaya bahwa dengan meningkatkan rasa kepedulian, dengan mempelajari hal-hal yang sebelumnya mereka tidak mereka pelajari dengan keberadaan mereka yang sama-sama riskan. Dengan pengetahuan ini dapat membuat terjadinya perubahan sosial, menuju masyarakat yang adil akan gender.

d. Feminisme PostModern

Gerakan feminisme postmodern hadir sebagai upaya untuk melakukan kritik dan otokritik terhadap patriarki atau sistem sosial yang menempatkan laki-laki sebagai pemegang kekuasaan utama bagi sebagian perempuan. Gerakan ini bertujuan untuk mendekontruksikan budaya perempuan melalui ikon perempuan baru yang tangguh, berani dan percaya diri. Dengan cara bergerak bebas, tidak tersempitkan oleh hanya satu pandangan apalagi dibatasi oleh defenisi tertentu.

\section{Pengertian Konsep Arsitektur Feminisme}

Menurut (Cronin, 2018) arsitektur feminisme merupakan seni dan ilmu yang mempelajari tentang merancang suatu objek yang secara geometri mengadopsi dibalik sifat keperempuanan. Sedangkan menurut (Silaban \& Punuh, 2011) feminisme itu sendiri memiliki makna dalam bidang arsitektur yaitu selain pengadopsian sifat perempuan mempunyai arti yang lebih dalam yaitu kebebasan dan kesejajaran dalam mengekspresikan ide dan desain bangunan.

Pengertian feminis secara makro adalah mengartikan segala hal yang berhubungan dengan perempuan baik dari sifatnya, penampilan, hingga perilakunya yang meliputi sosok feminisme. Adapun ciri feminis dalam fenomena sosial diantaranya:

a. Cara berpakain dalam menampilkan diri

b. Berperilaku baik, ramah, ceria serta lemah lembut

c. Kepekaan terhadap suatu perasaan

d. Kesensitifan terhadap suatu permasalahan

Ciri-ciri feminis diatas dapat menjadi satu acuan untuk menerapkan konsep feminisme pada pusat kcenatikan agar terciptanya kesinambungan bentuk.

\section{Penerapan Konsep Arsitektur Feminisme}

Menurut (Silaban \& Punuh, 2011) penerapan konsep arsitektur feminisme pada bangunan sebagai berikut:

a. Bentuk bangunan yang mengadopsi lekukan tubuh perempuan

Bentuk pada arsitektur feminisme harus menyelaraskan dengan fungsi objek yang akan dirancang. Maka dari itu konsep feminisme menggunakan bentuk ciri khas dari sifat keperempuanan yang memberi kesan elegan, dinamis, serta berestetika baik pada eksterior maupun interior objek rancangan. Selain itu, biasanya bentuk bangunan pada arsitektur feminisme memiliki bentuk tidak monoton dengan membuyarkan kejenuhan akibat kebosanan terhadap bangunan yang serba kotak, serta memiliki lengkungan pada setiap sudutnya yang diibaratkan seperti bentuk tubuh perempuan. Bukan hanya itu, aksesoris perempuan dapat dijadikan sebagai salah satu ide pendukung objek rancangan yang baik. Seperti pada gambar 1 dibawah ini yang merupakan bangunan museum Solomon R Guggenheim hasil dari karya Frank Lloyd Wright, bangunan ini mengadopsi bentukan bangunan yang menyerupai gelang perhiasan wanita ditambah ketika malam hari efek dari lampu didalam bangunan yang berwarna kuning oren memberikan kesan jelas seperti gelang emas perhiasan wanita yang cantik, elegan, dan mewah. 


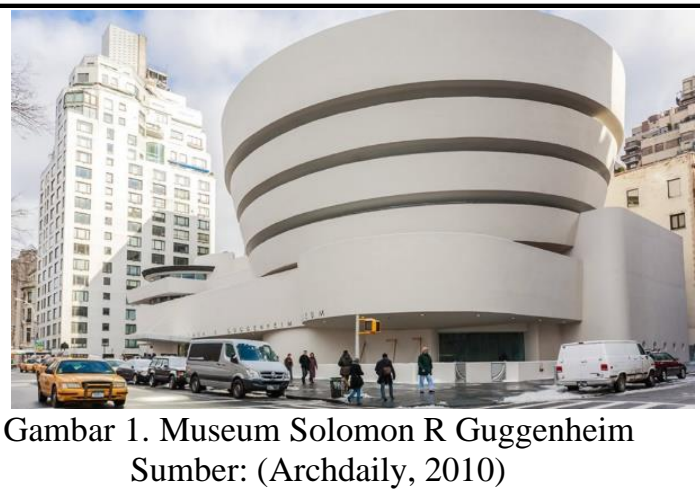

b. Fasad Bangunan Yang Berlekuk Sebagai Wujud Kelembutan Sifat Perempuan Dan Terlibatnya Kegiatan Wanita Di Dalam Konsep Bangunan

Fasad bangunan pada konsep feminisme dapat menunjukan adanya karakteristik dari bangunan tersebut yang elegan dan dinamis sehingga bentuknya berlekuk dan tidak monoton ataupun stream line yang dibuat agar menyerupai lekukan tubuh perempuan yang halus karena sebagian besar perempuan memiliki sifat yang lemah lembut. Seperti pada gambar 2 dibawah ini yang merupakan sebuah kampus di madrid ibu kota spanyol, bangunannya dilapisi logam panel agar terlihat lebih dinamis, indah, memiliki banyak lengkungan serta eksotis yang mencerminkan arsitektur feminisme. Selain itu, perempuan sebagian besar gemar mendandani atau merias wajahnya untuk mempercantik dirinya agar telihat feminim, sehingga tampilan bangunannya harus menyesuaikan konsep yang digunaka, dengan menggunakan kaca atau organik plastik pada bagian yang transparan. Menurut Pangkey, Rogi \& Siregar (2017) pengaplikasian material kaca tersebut akan menciptakan suatu estetika yang anggun dan elegan.

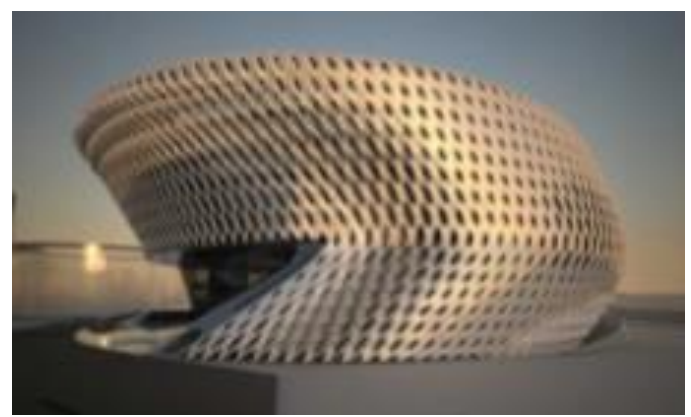

Gambar 2. Campus De La Justicia

Sumber: (inhabitat, 2008)

c. Penggunaan Warna Feminim Pada Bangunan

Pada arsitektur feminisme warna merupakan salah satu peran penting baik pada interior maupun eksterior bangunan, karena warna dapat mempengaruhi psikologis setiap manusia, khususnya perempuan. Penggunaan warna yang tepat juga dapat meningkatkan suasana hati manusia. Penentuan warna yang tepat, harus berdasarkan fungsi ruang yang akan ditunjang dengan mempertimbangkan faktor kenyamanan. Sehingga terciptanya ruang yang terasa lebih bebas saat pengguna beraktivitas. Setiap warna tentunya memiliki arti dan kesan yang berbeda pula. Warna yang sering digunakan pada seorang feminis adalah warna-warna lembut dan cerah. Ada beberapa warna dalam arsitektur feminisme yaitu:

Tabel 1. Karakter Warna

\begin{tabular}{|l|l|l|}
\hline No. & \multicolumn{1}{|c|}{ Warna } & \multicolumn{1}{c|}{ Karakter } \\
\hline 1. & Merah muda atau Pink & $\begin{array}{l}\text { Warna ini merupakan kombinasi dari warna merah dan putih. } \\
\text { Warna pink merupakan salah satu warna favorit bagi kaum } \\
\text { perempuan, yang dapat memberikan kesan feminim. Selain } \\
\text { menambah kesan feminim, warna pink juga dipercaya sebagai } \\
\text { warna yang menyimbolkan perasaan romantis, kasih sayang dan } \\
\text { penuh cinta. }\end{array}$ \\
\hline 2. & Kuning & $\begin{array}{l}\text { Warna kuning mampu memancarkan kehangatan dan rasa } \\
\text { bahagia pada seseorang, warna ini juga mengandung makna } \\
\text { optimis dan semangat yang tinggi. Dari sisi psikologi, warna } \\
\text { kuning dapat merangsang aktivitas dan mental. Oleh karena itu }\end{array}$ \\
\hline
\end{tabular}




\begin{tabular}{|l|l|l|}
\hline No. & Warna & \multicolumn{1}{|c|}{ Karakter } \\
\hline & & $\begin{array}{l}\text { } \\
\text { warna ini sangat cocok untuk penalaran yang logis, sehingga } \\
\text { orang yang menyukai warna kuning cenderung lebih bijaksana } \\
\text { dan pintar secara akademis, mereka lebih kreatif dan pandai } \\
\text { menciptakan ide baru. Namun jika terlalu banyak menggunakan } \\
\text { warna kuning pada suatu ruangan, dapat membuat kesan stress } \\
\text { dan gelisah }\end{array}$ \\
\hline 3. & Oranye & $\begin{array}{l}\text { Warna oranye adalah hasil dari kombinasi warna merah dan } \\
\text { kuning. Warna ini memberi keingintahuan dan memberi kesan } \\
\text { kehangatan. Dalam psikologi, warna ini melambangkan } \\
\text { petualangan, optimisme, vitalitas, keterampilan sosial, dan } \\
\text { kepercayaan diri. Warna ini memiliki kelompok warna yang } \\
\text { hangat, dengan karakteristik cerah, ceria, dapat membangkitkan } \\
\text { mood seseorang serta membangkitkan semangat. Nuansa oranye } \\
\text { tidak hanya diaplikasikan melalui cat, bisa juga diaplikasikan } \\
\text { pada jenis material, dan pencahayaan yang memiliki efek sejenis }\end{array}$ \\
\hline 4. & Ungu Muda & $\begin{array}{l}\text { Warna ungu muda merupakan warna feminim yang dapat } \\
\text { memberikan kesan keanggunan dan elegan yang telah dikaitkan } \\
\text { pada perempuan yang berkelas dan royaliti. Selain itu warna } \\
\text { ungu memiliki pemikiran yang kreatif dan kemampuan untuk } \\
\text { menghadapi kesulitan secara positif }\end{array}$ \\
\hline
\end{tabular}

d. Pembagian ruang yang jelas antara ruang privat dan publik yang memisahkan batasan laki-laki dan perempuan

Feminis menuntut adanya pembagian ruang dalam arsitektur untuk meningkatkan kualitas hidup mereka. Dimana mereka menginginkan pembagian ruang dalam arsitektur yang jelas antara ruang publik dan ruang privat dengan tambahan ruang yang lebih baik, seperti adanya dapur khusus dan taman pribadi. Hal ini dimaksudkan untuk memenuhi kebutuhan dasar akan identitas diri, kenyamanan dan rasa aman pada kaum perempuan.

\section{Pengertian Pusat Kecantikan}

Pusat kecantikan adalah sarana pelayanan umum atau wadah yang menyediakan fasilitas khususnya bagi perempuan untuk memanjakan dirinya agar lebih sehat dan percaya diri dalam berinteraksi sosial (Dessy, 2018). Fasilitas tersebut terdiri dari kesehatan kulit, rambut, dan tubuh dengan perawatan kosmetik secara manual dengan cara modern maupun tradisional tanpa tindakan operasi atau bedah.

Pusat kecantikan memiliki berbagai macam fasilitas, karena pada dasarnya kebutuhan perempuan dalam melakukan perawatan juga bermacam-macam. Mulai dari salon kecantikan yang merupakan tempat atau wadah khusus untuk memanjakan atau merawat diri bagi kaum perempuan seperti perawatan rambut, tubuh, wajah dan sebagainya, biasanya salon kecantikan dibagi menjadi dua tipe yaitu salon kecantikan yang menggunakan cara-cara tradisional dan salon kecantikan yang menggunakan alat-alat modern. Berbeda dengan salon kecantikan, klinik kecantikan biasanya didominasi menggunakan alat-alat yang canggih serta ditangani oleh ahli dibidangnya. Perawatan yang ditawarkan di klinik kecantikan pun beragam mulai dari perawatan wajah, tubuh hingga rambut. Selain itu, terdapat Spa yang merupakan tempat untuk memanjakan diri dari kepenatan pekerjaan dan rutinitas sehari hari.

\section{Metode Penelitian}

Demi berjalannya penelitian yang tepat dan sesuai dengan tujuan yang telah ditentukan, maka perlu menggunakan metode penelitian yang tepat. Penelitian kali ini menggunakan metode deskripsi kualitatif. Metode ini dilakukan dengan cara menyajikan deskripsi berupa tulisan dan gambaran nyata pada kondisi yang sebenarnya. Dimana pada metode ini menjelaskan secara rinci mengenai konsep arsitektur feminisme dan pusat kecantikan dengan cara mengumpulkan data yang berhubungan dengan objek penelitian tersebut.

Adapun dalam pengumpulan data yang dilakukan dalam penelitian ini yaitu data sekunder berupa studi literatur. Metode ini dilakukan guna mencari dan mengumpulkan berbagai data yang berkaitan dengan materi penelitian. Literatur yang sudah dikumpulkan kemudian dibaca dan dipahami hingga menemukan kesimpulan untuk dijadikan landasan teori dari penelitian ini. Studi literatur digunakan melalui browsing data di internet, 
membaca buku serta jurnal jurnal. Pusat kecantikan yang dijadikan studi kasus adalah erha derma center yang berlokasi di BSD,Serpong. Pemilihan dalam studi kasus tersebut karena bangunan erha derma center memiliki pendekatan terhadap konsep arsitektur feminisme.

Untuk menciptakan penelitian yang sesuai dengan yang diharapkan, maka dilakukan beberapa tahapan. Tahapan tahapan tersebut disusun secara sistematis dan terencana seperti gambar 3 dibawah ini:

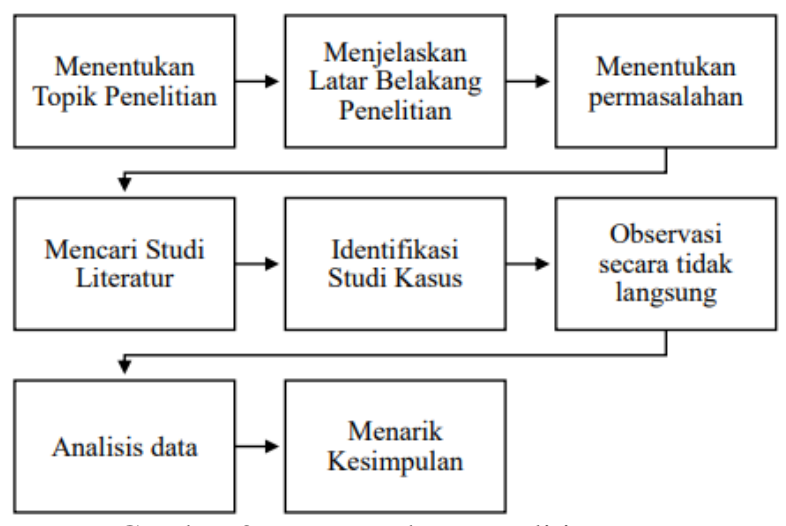

Gambar 3. Bagan Tahap Penelitian

Sumber: Archdaily, 2020

\section{Hasil dan Pembahasan}

\section{Erha Derma Center}

Erha derma center merupakan klinik kecantikan popular yang telah berdiri sejak tahun 1999 (Erha, 2019). Erha derma center sendiri merupakan klinik kecantikan untuk melayani kebutuhan masyarakat di bidang dermatologi. Erha derma center menawarkan berbagai macam perawatan kulit, mulai dari wajah, tubuh, hingga rambut. Dengan didukung oleh para ahli dermatologis yang sudah teruji di bidang tersebut serta menggunakan teknologi terkini. Sehingga, Erha klinik ini telah bertumbuh dan berkembang dengan memiliki 30 cabang yang terdapat di kota-kota besar di Indonesia, salah satunya yang berlokasi di Serpong Tangerang Selatan.

\section{Deskripsi Bangunan}

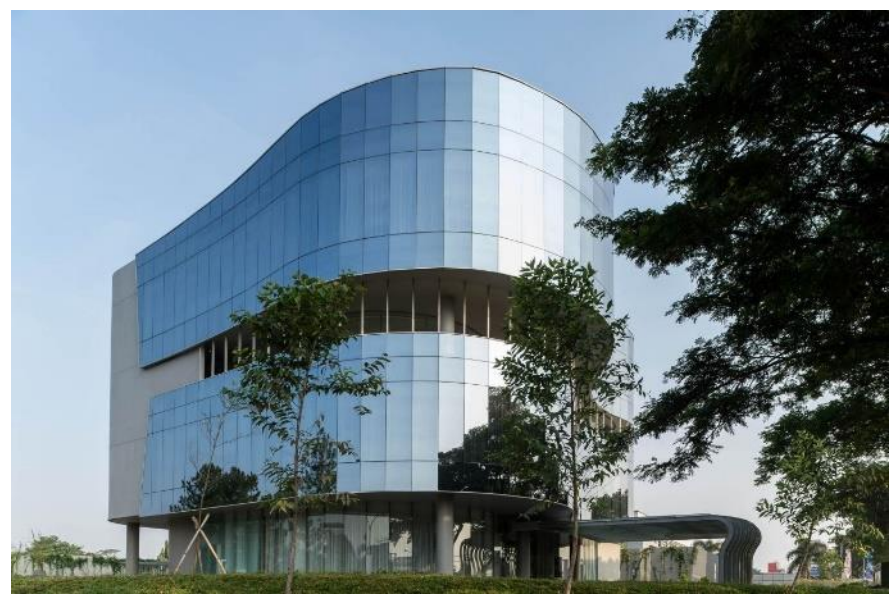

Gambar 4. Bangunan Erha Derma Center

Sumber: (Archdaily, 2013)

Nama Bangunan

Jenis

Arsitek

Luas Bangunan

Lokasi
: Erha Derma Center

: Bangunan Komersil

: HMP Architect

: $3350 \mathrm{~m}^{2}$

: Jl.Raya Serpong Kav. VIIC No.11, Lengkong Gudang,BSD,Serpong Sub-District South Tangerang City, Banten 1532. 


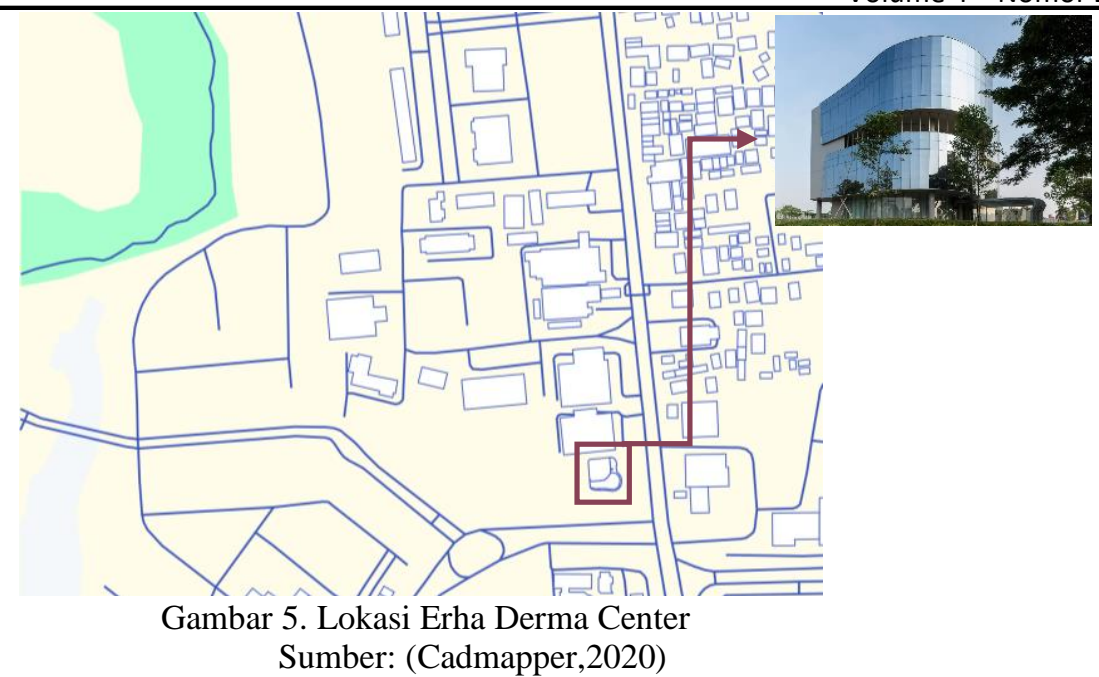

\section{Analisis Prinsip-Prinsip Konsep Arsitektur Feminisme Pada Bangunan Pusat Kecantikan}

\section{a) Bentuk Bangunan Yang Mengadopsi Lekukan Tubuh Perempuan}

Bangunan erha derma center mempunyai lekukan pada setiap sudut lantainya. Lekukan tersebut menyerupai tubuh perempuan pada umumnya. Hal itu bertujuan agar bangunan memiliki bentuk yang unik dan memecahkan deretan bangunan yang memiliki bentuk datar disekitarnya. Ide bentuk bangunan berawal dari bentuk kubus yang ditransformasikan dengan cara mengurangi sebagian volume nya, sehingga menghasilkan satu kesatuan yang utuh dari bentuk awal kubus menjadi bentuk desain bangunan yang bergelombang. Dapat dilihat pada gambar 6 dibawah ini.

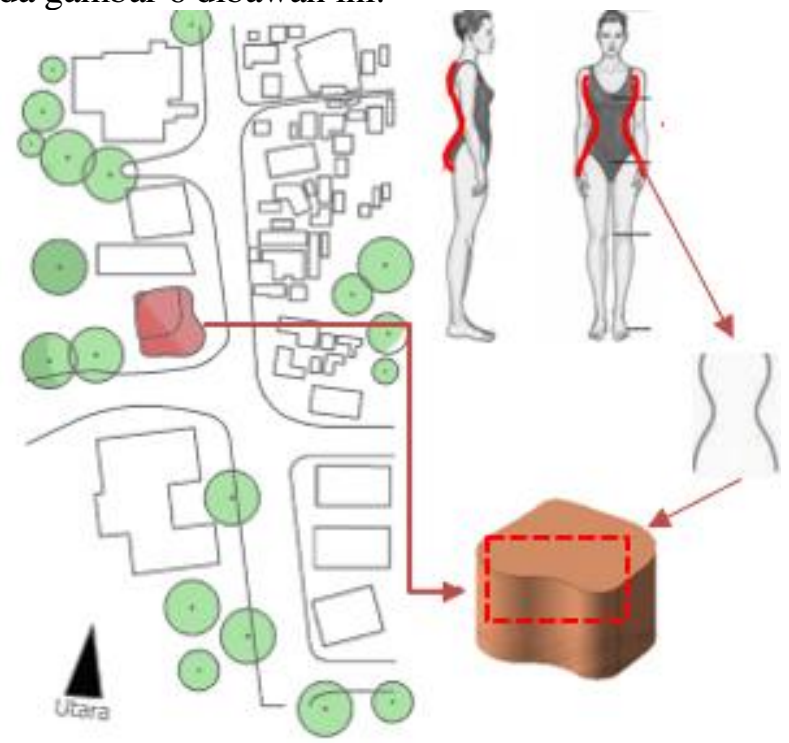

Gambar 6. Bentuk Bangunan Erha Derma Center

Sumber: (Analisis Peneliti, 2020)

\section{b) Analisis Fasad Bangunan Yang Berlekuk Sebagai Wujud Kelembutan Sifat Perempuan Dan}

\section{Terlibatnya Kegiatan Wanita Di Dalam Konsep Bangunan}

Pada bagian fasad terlihat lekukan atau stream line pada badan bangunan yang dibuat sedemikian rupa agar terlihat lembut dan elegan, karena lekukan tersebut mengadopsi dari salah satu sifat perempuan yang lemah lembut. Dengan didominasikan penggunaan kaca pada fasad yang terinspirasi dari penyimpanan alat rias perempuan. Hal itu karena sebagian perempuan yang gemar merias wajahnya, pasti memiliki tempat penyimpanan khusus untuk meletakan alat riasnya agar terlihat rapi, biasanya tempat penyimpanan tersebut terbuat dari plastic atau kaca yang terlihat lebih mewah. Maka dari itu material kaca diterapkan dalam bangunan Erha Derma Center. 


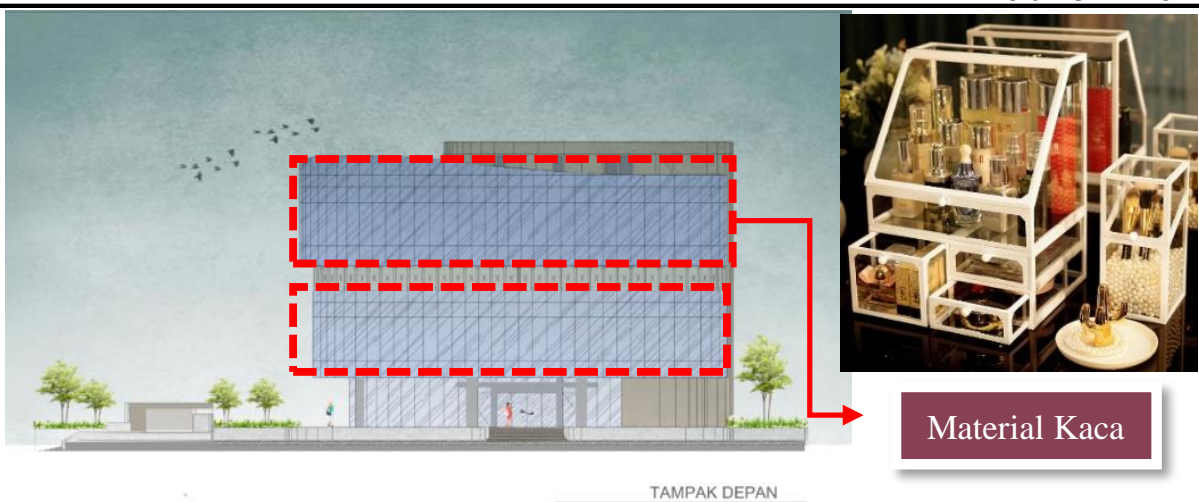

Gambar 7. Tampak Bangunan Erha Derma Center Sumber: (Analisis Peneliti,2020)

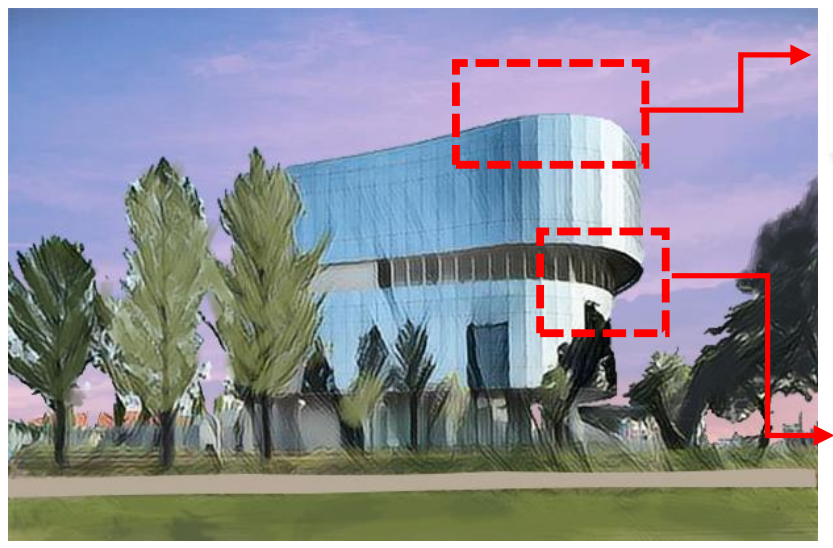

\section{Lekukan Pada Fasad}

Gambar 8. Fasad Bangunan Erha Derma Center Sumber: (Analisis Peneliti,2020)

Jika fasad bagian depan bangunan erha derma center didominasi dengan material kaca pada bagian yang transparan, namun tidak semua sisi bangunan menggunakan material tersebut. Pada bagian fasad belakang bangunan dilapisi material beton dengan adanya bukaan yang tidak terlalu besar sehingga membuat matahari masuk ke dalam ruangan dibagian belakang. Pengaplikasian material beton, bertujuan untuk menyesuaikan fungsi bangunan di dalamnya. Yang mana fungsi ruang bagian belakang bangunan merupakan area privasi seperti ruang makan dokter, kamar mandi, gudang dan lain sebagainya.

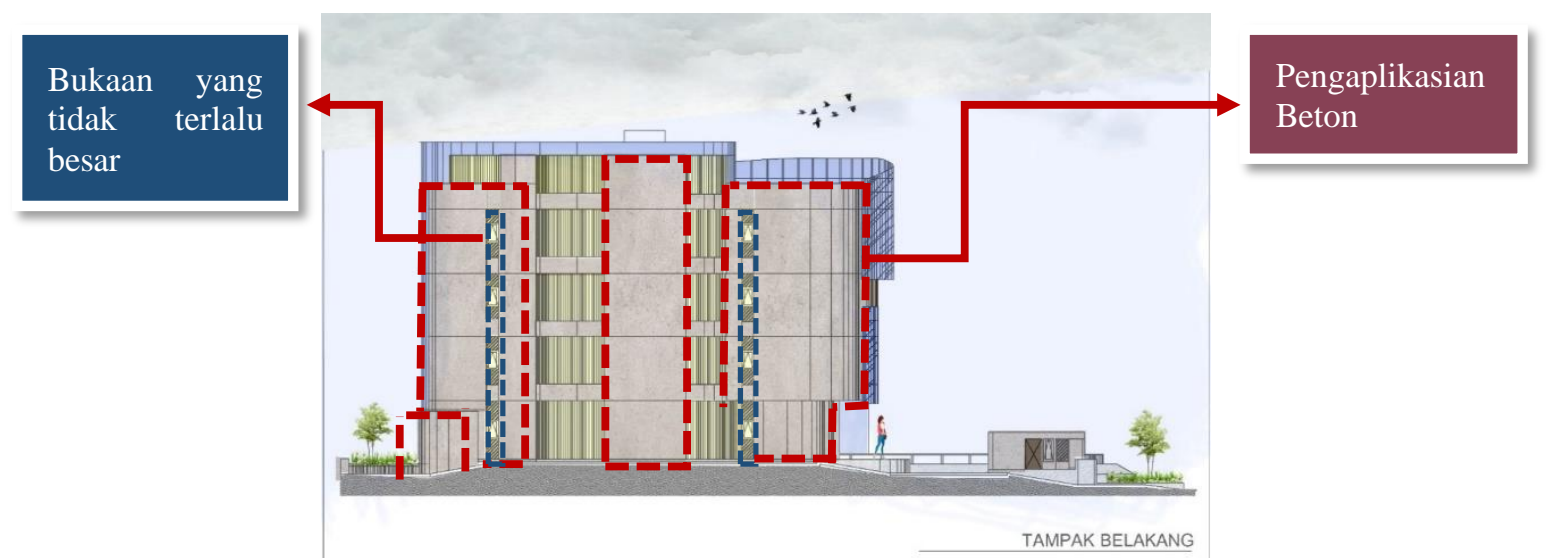

Gambar 9. Tampak Belakang Erha Derma Center Sumber: (Analisis Peneliti,2020)

\section{c) Analisis Penggunaan Warna Feminim Pada Bangunan}

Penggunaan warna pada interior bangunan erha derma center didominasi menggunakan warna netral atau warna pastel. Dinding dilapisi warna putih dengan perpaduan material vinyl kayu yang berwarna coklat pada ornamen dinding sehingga terlihat lembut dan elegant seperti pakaian yang digunakan pada model di gambar 5. Pemilihan warna pada sebagian furniture menyesuaikan warna pada dinding seperti sofa yang 
dilapisi kain berwarna coklat muda dan bantal sofa dengan perpaduan warna coklat dan oranye. Kemudian adanya warna netral pada kasur ruang konsultasi berwarna putih serta lemari berwarna hitam. Hal ini menunjukan sebagian warna-warna tersebut merupakan penerapan dari ciri warna feminim.

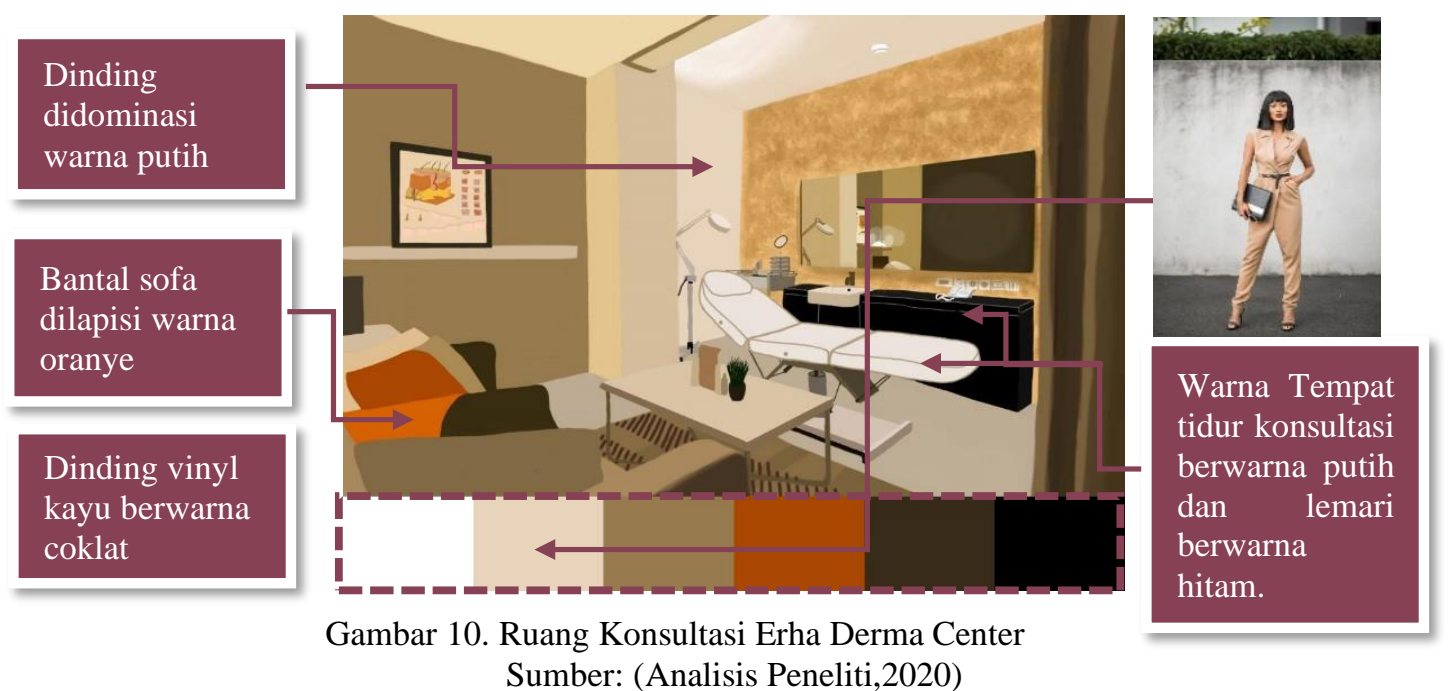

Fasad bangunan erha derma center dilapisi warna biru muda, pengaplikasian warna tersebut dengan mempertimbangkan ide desain bangunan yang berbentuk bergelombang seperti ombak air di laut. Terciptanya warna biru muda pada fasad dikarenakan menggunakan material kaca sebagai bahan utama.

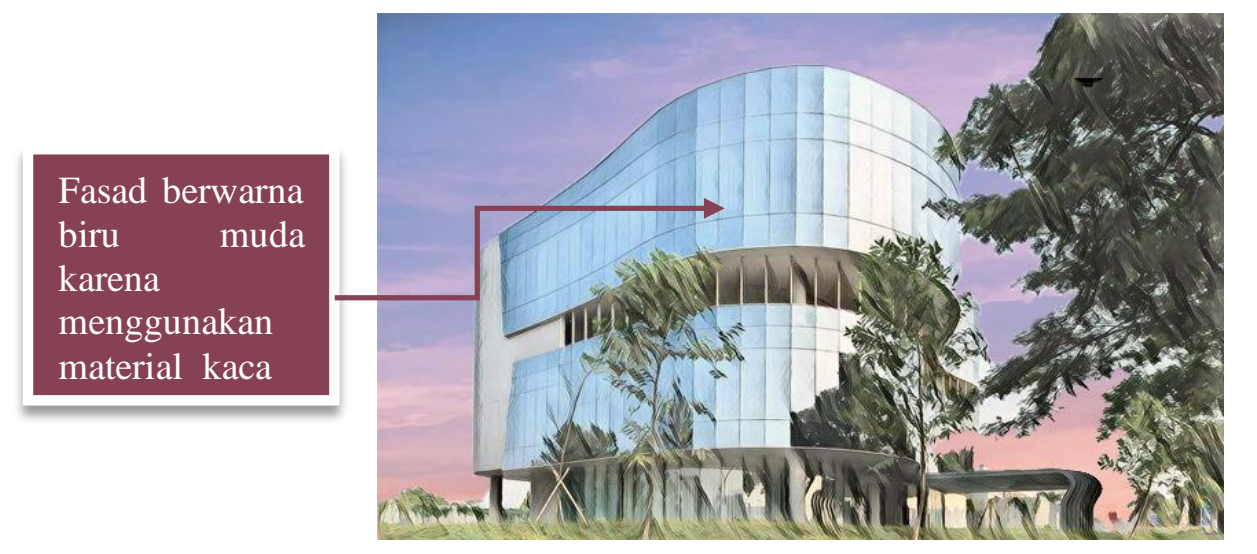

Gambar 11. Warna Fasad Erha Derma Center Sumber: (Analisis Peneliti,2020)

\section{d) Pembagian Ruang Yang Jelas Antara Ruang Privat Dan Publik Yang Memisahkan Batasan \\ Laki-Laki Dan Perempuan}

Bangunan erha derma center pada lantai dasar dibagi menjadi beberapa area meliputi, area publik (zona hijau) seperti adanya ruang tunggu, konter yang menjual produk erha, pendaftaran, kasir dan informasi. Lalu area semi publik (zona coklat) seperti lift pengunjung yang dekat dengan area publik, namun untuk bisa mengakses lift ke lantai atas pengunjung harus melakukan pendaftaran terlebih dahulu. Kemudian area privat (zona merah) berada diantara area semi privat dan area publik seperti ruang medical record yang merupakan tempat untuk menyimpan data-data pasien. Area semi privat (zona biru) seperti lift pegawai, ruang farmasi yang satu area dengan ruang apoteker. Serta area servis (zona kuning) seperti toilet dan gudang office boy (OB). Pembagian ruang pada lantai dasar membuat area publik sebagai area utama yang dapat menghubungkan ke area-area lainnya, sehingga menciptakan kejelasan pada ruang dengan adanya pembatas di setiap ruang yang membentuk area berdasarkan fungsinya 

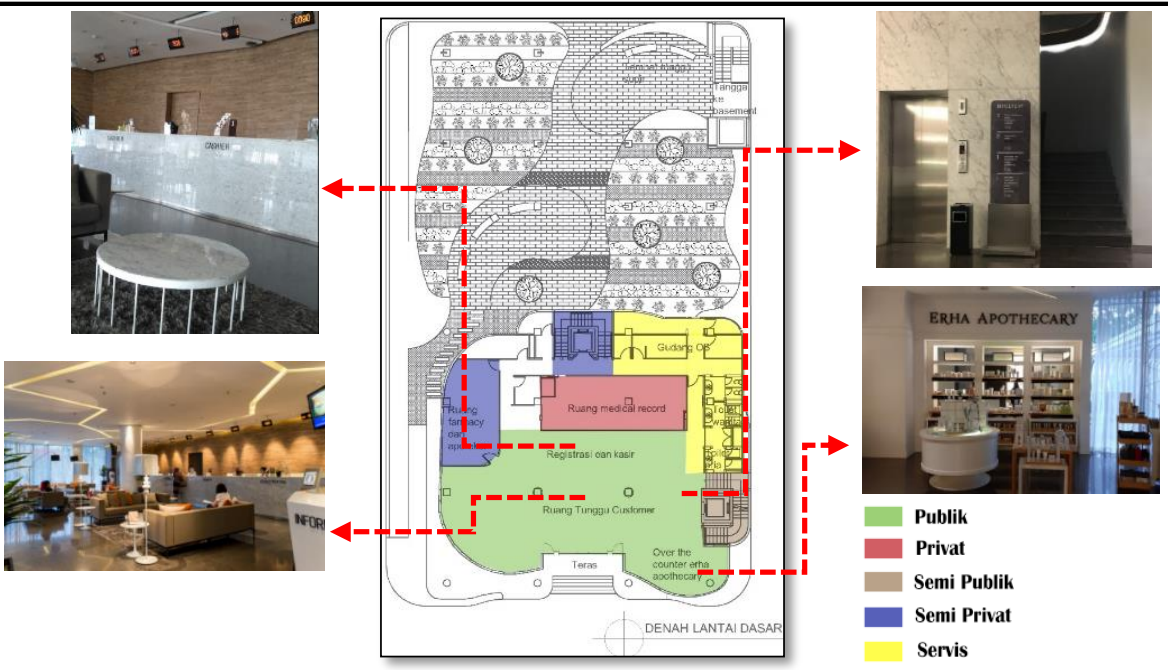

Gambar 12. Denah lantai dasar Erha Derma Center Sumber: (Analisis Peneliti,2020)

Lantai satu pada bangunan erha derma center dibagi menjadi enam area, sama halnya dengan lantai dasar. Pada umumnya area publik (zona hijau) seperti ruang tunggu, kasir serta tempat bermain anak. Kemudian area semi publik (zona coklat) tidak jauh berbeda dengan lantai dasar seperti adanya lift pengunjung. Berbeda dengan lantai dasar untuk area privat (zona merah) pada lantai satu digunakan sebagai ruang makan khusus untuk dokter. Sedangkan area semi privat (zona biru) seperti ruang konsul, stasiun perawat, serta lift khusus pegawai. Kemudian ruang servis (zona kuning) adanya gudang dan toilet. Pembagian ruang pada lantai satu memiliki perbedaan pada lantai dasar, akan tetapi area publik tetap menjadi area utama pada lantai satu yang bertujuan untuk menghubungan ke area lainnya. Perbedaan ruang timbul karena adanya fungsi ruang yang berbeda dengan lantai dasar, ini membuktikan bahwa adanya perbedaan ruang tetap memberikan kejelasan dengan adanya pembatas ruang.

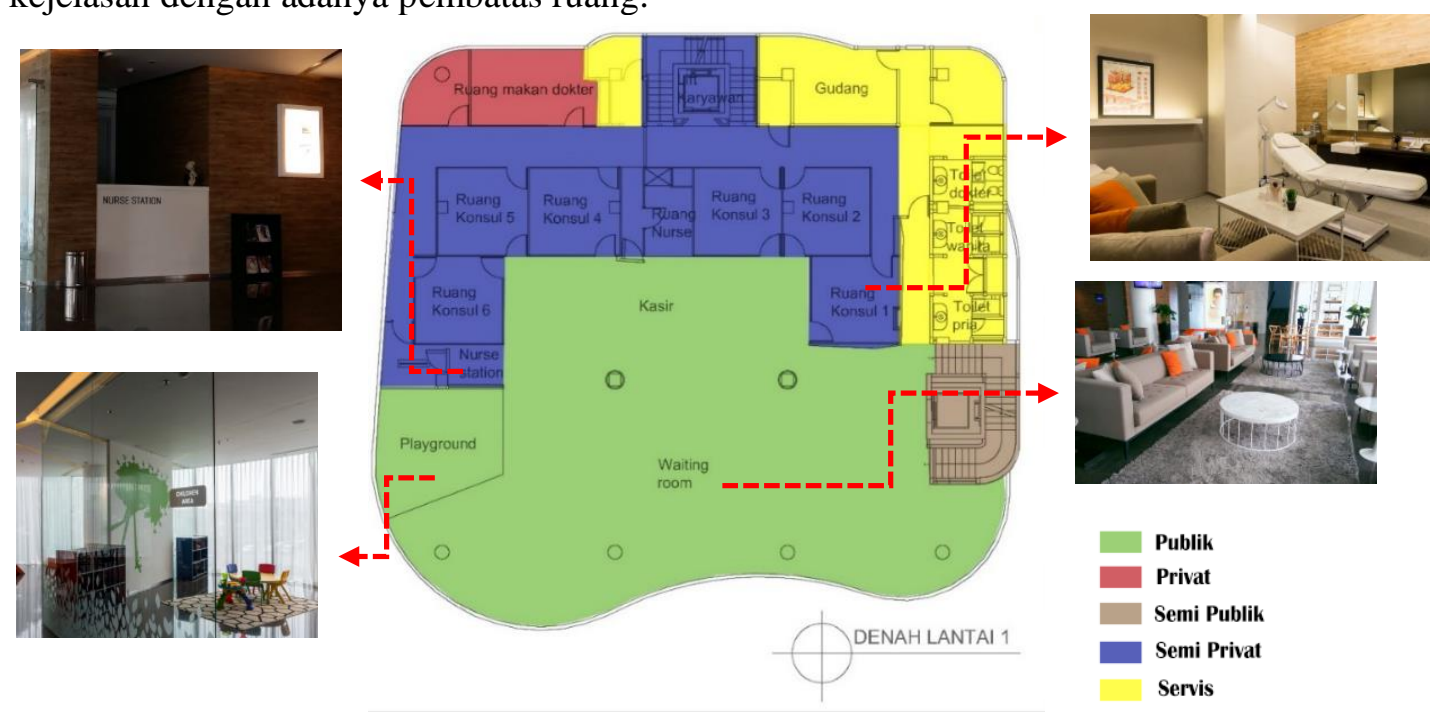

Gambar 13. Denah lantai satu Erha Derma Center Sumber: (Analisis Peneliti,2020)

Lantai 2 berbeda dengan lantai-lantai sebelumnya yang mana terdapat ruang facial yang diberi batasan antara laki-laki dan perempuan dengan tujuan agar perempuan dapat merasakan kenyamanan dan kebebasan saat melakukan kegiatan facial, dengan diberinya pembatas ruang tersebut. Namun ruang lainya pada lantai 2, memiliki ruang dan fungsi yang sama pada lantai sebelumnya, seperti adanya ruang tunggu, ruang OB, panel listrik, toilet dan area kasir. Yang berbeda pada lantai-lantai sebelumnya ialah adanya area ruang makan pegawai dan pantry serta ruang facial. Dapat dilihat pada gambar dibawah ini 


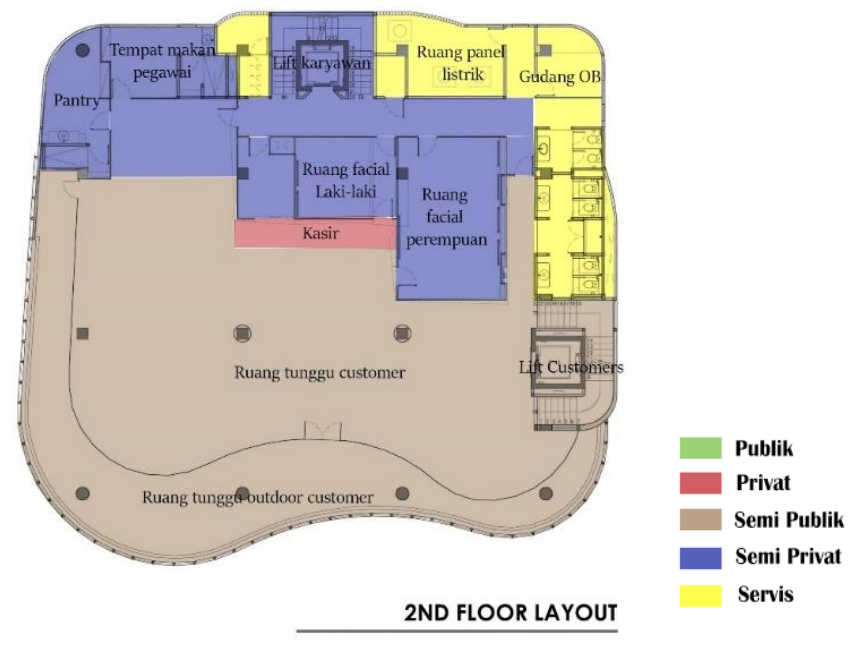

Gambar 14. Denah Lantai Dua Erha Derma Center Sumber: (Analisis Peneliti,2020)

\section{Kesimpulan}

Kesimpulan yang sudah didapatkan setelah melakukan analisis terhadap studi kasus Erha Derma Center, bahwa bangunan tersebut sudah memenuhi kriteria yang sesuai konsep arsitektur feminisme dalam penerapannya. Seperti bentuk bangunan yang memiliki lekukan menyerupai tubuh perempuan dengan maksud agar terlihat dinamis dan elegan. Kemudian fasad bangunan juga mengikuti bentuk bangunan yang memiliki lengkungan yang halus pada setiap sudutnya, dimana lengkungan tersebut terinspirasi dari sifat perempuan yang lemah lembut maka dibuatlah lekukan yang halus pada fasadnya. Selain itu fasad juga menggunakan material kaca karena mengadopsi dari penyimpanan alat rias perempuan. Hal itu karena sebagian perempuan yang gemar merias wajahnya, pasti memiliki tempat penyimpanan khusus untuk meletakan alat riasnya agar terlihat rapi, biasanya tempat penyimpanan tersebut terbuat dari plastik atau kaca yang terlihat lebih mewah. Lalu pada bagian interiornya menggunakan warna-warna soft, seperti warna coklat muda yang merupakan warna feminim agar terlihat cantik dan elegant. Selain itu, pembagian ruangnya pun jelas dengan diberi batasan antara ruang facial laki-laki dan perempuan dengan maksud agar perempuan merasakan kenyamanan dan kebebasan pada saat melakukan kegiatan didalamnya.. Hal itu menunjukan kekonsistenan bangunan erha derma center dalam penerapannya, adanya konsep arsitektur feminisme bertujuan untuk membuat perempuan merasakan kenyamanan dan keamanan saat melakukan berbagai perawatan pada pusat kecantikan Erha Derma Center.

\section{Referensi}

Amin, S. (2013). Pasang Surut Gerakan Feminisme. Marwah: Jurnal Perempuan, Agama Dan Jender, 12(2), 146. https://doi.org/10.24014/marwah.v12i2.520

Archdaily. (2010). AD Classics: Solomon R. Guggenheim Museum / Frank Lloyd Wright. Www.Archdaily.Com. https://www.archdaily.com/60392/ad-classics-solomon-r-guggenheim-museumfrank-lloyd-wright?ad_source=search\&ad_medium=search_result_projects

Archdaily. (2013). Eau Building / HMP Architects. Www.Archdaily.Com. https://www.archdaily.com/369623/eau-building-hmp-architects

Badu, R., Egam, E., \& Rompas, L. (2019). Beauty mall di Manado “Arsitektur Feminisme.” Jurnal Arsitektur Daseng Unsrat Manado, Vol 8, No. https://ejournal.unsrat.ac.id/index.php/daseng/article/view/23661

Cronin, E. (2018). ARCHITECTURE AND FEMINISM: DISCUSSIONS TOWARDS INCLUSIVE IDEOLOGIES, PEDAGOGIES, AND PRACTICES. University of florida.

Dessy, V. (2018). Beauty care center di Kota Pontianak. Jmarsitek, 6(1), 293-305.

Erha. (2019). ERHA milestone \& value. Www.Erha.Co.Id. https://erha.co.id/story

inhabitat. (2008). Civil Court for Madrid from Zaha Hadid. Www.Inhabitat.Com. https://inhabitat.com/civilcourt-for-madrid-from-zaha-hadid/zaha-hadid-hadid-madrid-civil-court-building-zaha-hadid-courtbuilding-madrid-campus-de-la-justicia-spain-civil-court-building-double-facade-intelligent-facadebuilding-envelope-high-perform/ 
Lebond, B. (2007). Arti dan Pengaruh Warna bagi Psikologi Manusia. Warna dapat Mempengaruhi Mood. http://ayulestariok.blogspot.com/2018/04/makalah-psikologi-warna.html

Melati, N. (2020). Membicarakan Feminisme. EA Books.

Retnani, S. (2017). FEMINISME DALAM PERKEMBANGAN ALIRAN PEMIKIRAN DAN HUKUM DI INDONESIA. Jurnal Ilmu Hukum Principium, Vol 1 No 1, 95-109.

Silaban, C., \& Punuh, C. . (2011). Arsitektur Feminisme. Media Matrasain, VOL 8 NO 2, 29-39.

Sya'bania, S., Mauliani, L., \& Sari, Y. (2019). DAPTASI BENTUK BANGUNAN PUSAT PEMBERDAYAAN EKONOMI PEREMPUAN DI BEKASI TERHADAP KONDISI LAHAN. Purwarupa, Volume 3 N, 57-64.

Thompson, B. (2007). Mindfulness, Self-Esteem, And Unconditional SelfAcceptance. Journal of RationalEmotive \& Cognitive-Behavior Therapy. Journal of Rational-Emotive \& Cognitive-Behavior Therapy, Vol. 26, N. https://link.springer.com/article/10.1007\%2Fs10942-007-0059-0 